\title{
L’immunothérapie dans le cancer épithélial de l'ovaire : entre espoir et réalité.
}

\section{Immunotherapy in epithelial ovarian carcinoma: hope and reality}

Vincent Lavoué ${ }^{1,2,3, *}, \mathrm{MD}, \mathrm{PhD}$, Fabrice Foucher ${ }^{1}, \mathrm{MD}$, Sébastien Henno ${ }^{4}$, MD, Estelle Bauville ${ }^{1}$,

MD, Véronique Catros ${ }^{2,3,5}$, PharmD, PhD, Florian Cabillic ${ }^{2,3,5}$, PharmD, PhD, Jean Levêque ${ }^{1,2}, \mathrm{MD}$, $\mathrm{PhD}$,

${ }^{1}$ Service de chirurgie gynécologique. Centre Hospitalier Universitaire de Rennes. France.

${ }^{2}$ Faculté de médecine, Université de Rennes 1, Rennes, France

${ }^{3}$ Inserm, UMR991, Rennes, France

${ }^{4}$ Service d'anatomo-pathologie, Centre Hospitalier Universitaire de Rennes, France

${ }^{5}$ Service de biologie cellulaire, Centre Hospitalier Universitaire de Rennes, France

* Auteur correspondant: Vincent Lavoué, MD, PhD, service de chirurgie gynécologique, CHU Hôpital Sud, 16 Bd de Bulgarie, 35000 Rennes, France.vincent.lavoue@gmail.com

Les auteurs ne déclarent aucun conflit d'intérêt. 
Titre courant :

Immunologie du cancer de l'ovaire 


\section{Résumé :}

Introduction : Le cancer épithélial de l'ovaire (CEO) présente un pronostic sombre avec depuis deux décennies des progrès très modestes en terme de gain de survie. L'immunologie, longtemps négligée dans le CEO, apparait maintenant central dans l'histoire naturelle de cette maladie cancéreuse. L'objet de cette revue est une mise au point sur l'état des connaissances sur l'immunologie dans le CEO et la potentielle place de l'immunothérapie dans son traitement futur.

Matériel et méthodes : Interrogation de la base de données MedLine en utilisant les mots clés : « Ovarian carinoma, immunotherapy, $\mathrm{T}$ lymphocyte, regulator $\mathrm{T}$ lymphocyte, dendritic cells, macrophage, antigen, chemotherapy, surgery, clinical trials ». Nous avons retenu les éléments pertinents pour la compréhension de l'immunologie du CEO, de la place des traitements conventionnels et des stratégies d'immunothérapie à partir des articles de langue anglaise et française.

Résultats: L'infiltration intra-tumorale par des cellules immunitaires conditionnent de manière majeure le pronostic du CEO. Les traitements traditionnels du CEO que sont la chirurgie et la chimiothérapie diminuent l'immunosuppression de la patiente. L'immunologie est l'une des composantes de l'action thérapeutique de la chimiothérapie et de la chirurgie. L'immunothérapie après des résultats décevants est à l'aube d'une révolution thérapeutique en cancérologie par l'arrivée de drogue ciblant le microenvironnement tumoral tolérogène.

Conclusion: L'immunologie conditionne l'histoire naturelle du CEO. La modulation de l'immunosuppression associée à une stimulation de l'immunité antitumorale est probablement l'une des prochaines révolutions thérapeutiques en cancérologie. 


\section{Summary:}

Introduction: Epithelial ovarian carcinoma (EOC) has a worst prognosis with little progress in term of survival for the last two decades. Immunology received little interest in EOC in the past, but now appears very important in the natural history of this cancer. This review is an EOC immunology state of art and focuses on the place of immunotherapy in future.

Material and methods: A systematic review of published studies was performed. Medline baseline interrogation was performed with the following keywords: « Ovarian carinoma, immunotherapy, $\mathrm{T}$ lymphocyte, regulator $\mathrm{T}$ lymphocyte, dendritic cells, macrophage, antigen, chemotherapy, surgery, clinical trials ». Identified publications (English or French) were assessed for the understanding of EOC immunology and the place of conventional treatment and immunotherapy strategy.

Results: Intratumoral infiltration by immune cells is a strong prognosis factor in EOC. Surgery and chemotherapy in EOC decrease imunosuppression in patients. The antitumoral immunity is a part of the therapeutic action of surgery and chemotherapy. Until now, immunotherapy gave some disappointing results, but the new drugs that target the tolerogenic tumoral microenvironnement rise and give a new hope in the treatment of cancer.

Conclusion: Immunology controls the EOC natural history. The modulation of immunosuppressive microenvironment associated with the stimulation of antitumoral immunity could be the next revolution in the treatment of cancer. 
Mots clés : cancer de l'ovaire, immunologie, lymphocyte, immunothérapie, immunomodulation, microenvironnement

Key words: ovarian carcinoma, immunology, lymphocyte, immunotherapy, immunomudulation, microenvironment 


\section{Introduction}

Le cancer épithélial de l'ovaire (CEO) est le $5^{\text {ième }}$ cancer le plus fréquent et la $4^{\text {ième }}$ cause de mortalité par cancer chez les femmes dans les pays industrialisés [1]. Son pronostic est sombre avec une survie globale à 5 ans de 30\%. La majorité des patientes récidivent dans les 12-18 mois qui suivent la fin du traitement et vont mourir de leur maladie cancéreuse malgré une réponse initiale au traitement satisfaisante [2, 3]. Quinze pour cent des patientes meurent dans l'année du diagnostic, décès souvent lié à une chimiorésistance initiale. Malgré des efforts constants pour une chirurgie de debulking exhaustive [4] et une chimiothérapie qui peut être adjuvante ou néo-adjuvante [5], il n’y a pas eu de diminution significative du taux de mortalité par cancer de l'ovaire depuis les deux dernières décennies. De même, les dernières molécules proposées dans le cancer de l'ovaire comme les antiangiogéniques ont montré une certaine efficacité avec une amélioration de quelques mois prouvée sur la survie sans récidive mais par contre avec un gain sur la survie globale qui reste à démontrer [6].

Le CEO ne semble pas profiter des progrès réguliers observés dans les autres pathologies tumorales où de nouvelles molécules apportent des bénéfices à la survie des patientes comme par exemple le Trastuzumab (Herceptin®) dans le cancer du sein [7], l'Imatinib (Glivec®) dans certaines hémopathies [8] ou encore le Sorafenib (Nexavar®)dans le cancer hépato-cellulaire [9]. L’un des axes de recherche pour la découverte de nouveaux traitements dans le CEO est l'immunologie. L'amélioration des connaissances dans la relation entre les cellules tumorales et les cellules immunitaires de la patiente ouvre la porte de nouvelles stratégies thérapeutiques dans le CEO. Ces nouvelles stratégies ne ciblent pas simplement la cellule tumorale mais aussi les cellules immunitaires de la patiente pour permettre une réactivation de celles-ci et leur permettre de détruire ou tout au moins contenir la progression tumorale. L'objet de cette revue est une mise au point sur l'immunologie du cancer de l'ovaire et de son impact sur le pronostic de la maladie tumorale ovarienne. L'impact des traitements conventionnels du CEO que sont la chirurgie et la chimiothérapie sur l'état d'immunosuppression des patientes est également détaillé. Enfin, les essais cliniques 
d'immunothérapies réalisés dans le CEO sont décrits ainsi que les promesses thérapeutiques que ces immunothérapies portent. 
Matériel et méthodes :

La base de données MedLine a été interrogée en utilisant les mots clés : " Ovarian carinoma, immunotherapy, $\mathrm{T}$ lymphocyte, regulator $\mathrm{T}$ lymphocyte, dendritic cells, macrophage, antigen, chemotherapy, surgery, clinical trials ». Les éléments pertinents pour la compréhension de l'immunologie du CEO, de la place des traitements conventionnels et des stratégies d'immunothérapie à partir des articles de langue anglaise et française ont été retenus. 


\section{L'impact du système immunitaire sur le pronostic du cancer épithélial de l'ovaire}

Le CEO, comme la plupart des cancers, est une tumeur immunogène, c'est-à-dire qu'elle exprime ou surexprime des Antigènes (Ag) de tumeur. Ces Ag de tumeur sont acquis par la cellule tumorale dans son processus de transformation néoplastique et sont capables de générer une réaction immunitaire antitumorale humorale, via des anticorps (Ac), ou cellulaire via des cellules cytotoxiques comme par exemple les lymphocytes $\mathrm{T} \mathrm{CD} 8^{+} .[10,11]$. Le premier Ag de tumeur découvert dans le CEO est la protéine HER2/neu, récepteur membranaire impliqué dans la prolifération cellulaire [12]. D'autres Ag de tumeur ont été identifiés dans le CEO comme le Ca125, le Ca15.3 [13], le récepteur $\alpha$ aux folates [14], EpCAM (Epithelial cell adhesion molecule) [15], TP53 [10] ou encore les Ag du groupe testis (NY-ESO1, MAGE, BAGE...) [16]. Ces Ag de tumeurs permettent à «l'hôte » de déclencher une réaction immunitaire dite adaptative, dirigée contre les cellules tumorales, reconnues comme des cellules du «non soi ». Cette réaction est médiée par des cellules immunitaires cytotoxiques qui vont infiltrer la tumeur pour exercer leur action antitumorale. Cette infiltration lymphocytaire tumorale par des TIL (lymphocyte intra tumoral) va conditionner le pronostic de la patiente. Ainsi, Zhang et al ont ainsi pu démontrer que la présence de TIL était un facteur pronostic majeur: toutes patientes confondues (réponse complète, incomplète ou nulle à la chirurgie et la chimiothérapie) l'absence de TIL implique une survie à 5 ans de moins de 5\% [17]. Pour les patientes avec une réponse complète à la chirurgie et à la chimiothérapie, la présence de TIL définit un groupe de patientes avec un taux de survie à 5 ans de $73 \%$ tandis que l'absence de TIL rend un taux de survie à 5 ans de moins de 5\% [17]. Suite à cette publication princeps, plusieurs travaux ont confirmé l'implication des TIL dans le pronostic du CEO en détaillant la nature de l'infiltrat lymphocytaire cytotoxique par différents marqueurs de différenciation lymphocytaire : le marqueur CD3 désigne l'ensemble des lymphocytes, le marqueur CD8 désigne les lymphocytes T CD8 qui sont des lymphocytes cytotoxiques, bras armé de la réponse immunitaire adaptative (cf tableau $\mathrm{n}^{\circ} 1$ ). D'autres travaux ont également montré l'implication de l'immunité dite « innée » dans la réponse anti-tumorale et donc dans le pronostic de la maladie. Un taux et une activité élevés d'effecteurs immuns innés comme les Natural Killer (NK) ou les lymphocytes $\mathrm{T}$ V $\gamma 9 \mathrm{~V} \delta 2$ ont montré un impact positif sur la survie des patientes $[18,19]$. 
Cette infiltration lymphocytaire intra-tumorale est le témoin d'une «immunosurveillance» antitumorale. Si la preuve de l'immunité anti-tumorale ne fait plus aucun doute, celle-ci est toutefois dépassée permettant l'échappement tumoral et donc le développement d'un cancer. En effet, la tumeur développe des mécanismes de contournement pour éviter la lyse tumorale médiée par les effecteurs immuns cytotoxiques et permettre sa progression. Le développement d'un cancer est résumé par le concept de « l'immunoediting » qui propose trois phases successives [34]. La première phase est la phase d'élimination où le système immunitaire est capable de détecter et détruire les clones cellulaires en transformation tumorale. Elle est suivie par la phase d'équilibre, phase de latence pouvant durer plusieurs années durant laquelle les clones cellulaires variants émergeants portent plusieurs mutations génétiques conférant une plus haute résistance aux attaques du système immunitaire. Cette phase d'équilibre est illustrée par les observations cliniques où des tumeurs de donneurs d'organe sont transmises à des individus receveurs d'une greffe d'organe [35]. Enfin, à l'issue du processus d'équilibre, des clones cellulaires transformés arrivent à échapper complètement à la surveillance exercée par le système immunitaire. Pendant cette phase d'échappement, la tumeur n'est plus détectée, ni éliminée par le système immunitaire. Cette phase induit un climat d'immunotolérance favorable à la croissance tumorale et apparait la tumeur qui devient alors symptomatique et détectable cliniquement. Cet échappement tumoral implique plusieurs acteurs : la cellule tumorale elle-même, les cellules immunitaires et les cellules du stroma. Les cellules tumorales vont par exemple diminuer l'expression de protéines membranaires impliquées dans la présentation de l'Ag au système immunitaire, se rendant ainsi invisibles [27]. Les cellules tumorales vont aussi augmenter l'expression de molécule membranaire comme PD-L1 (Programmed death-1 ligand), capable d'être reconnu par PD-1 (programmed death-1) exprimé par les lymphocytes T CD8+ dont l'engagement diminue fortement leurs fonctions cytotoxiques et pro-inflammatoires anti-tumorales [22, 36, 37]. Enfin, les cellules tumorales peuvent aussi sécréter des facteurs solubles immunosuppresseurs comme l'enzyme IDO (indolamine-2,3-dioxygénase), qui sert à la tolérance immunitaire dans différents contextes physiologiques comme la grossesse mais dont la fonction est détournée par la tumeur [38-40]. L'expression d'IDO est corrélé à une dissémination tumorale plus importante et avec un mauvais 
pronostic dans le CEO [38, 39, 41, 42]. Les cellules immunitaires jouent également un rôle majeur dans l'immunosuppression et donc la tolérance de la tumeur.

Le microenvironnement tumoral recrute des cellules immunitaires tolérogènes qui vont, par des contacts cellulaires ou via des molécules solubles (comme le TGF- $\beta$ (transforming growth factor) ou l'interleukine 10), inactiver les cellules cytotoxiques effectrices comme les lymphocytes $\mathrm{T} \mathrm{CD} 8^{+}$. Il existe plusieurs populations de cellules immunitaires responsables de la tolérance tumorale. On retrouve les lymphocytes $\mathrm{T}$ régulateurs, caractérisés par leur phénotype $\mathrm{CD} 4{ }^{+} \mathrm{CD} 25^{+} \mathrm{FoxP} 3^{+}$, les cellules dendritiques tolérogènes ou encore les macrophages associés à la tumeur (TAM) (figure 1). L'infiltration tumorale par ces différents types de cellules immunitaires est corrélée à une survie diminuée dans les séries cliniques de cohorte (tableau $\mathrm{n}^{\circ} 2$ ). Les cellules immunitaires systémiques ont également un impact sur le pronostic du CEO. La lymphopénie est un facteur de mauvais pronostic qui est significativement associée à un stade FIGO (Fédération Internationale des Gynécologies Obstétriciens) plus élevé et une survie plus courte [43, 44]. L'aspect qualitatif c'est-à-dire phénotypique ou fonctionnel (sécrétion de cytokines pro-inflammatoires ou capacités cytotoxiques) des effecteurs immuns sanguins est également corrélé au pronostic de la patiente dans le CEO [18, 19].

Le troisième type cellulaire impliqué dans l'échappement immunitaire dans le CEO correspond aux cellules stromales, parmi lesquelles on retrouve les cellules endothéliales vasculaires ou encore les cellules souches mésenchymateuses. Les cellules endothéliales peuvent participer à l'échappement immunitaire de la tumeur en exprimant le récepteur à l'endothéline $\mathrm{B}\left(\mathrm{ET}_{\mathrm{B}} \mathrm{R}\right)$ qui va diminuer le recrutement des lymphocytes cytotoxiques intra-tumoraux et donc s'associer à une diminution de la survie dans le CEO [49]. Les cellules souches mésenchymateuses sont également impliquées en sécrétant par exemple la prostaglandine E2, puissant immunosuppresseur [52].

Le microenvironnement tumoral est donc caractérisé par de nombreuses molécules immunosuppressives, solubles ou membranaires, produites par différentes sources cellulaires (tumorales, immunitaires ou stromales) qui interagissent entre-elles. Ce réseau fait de boucles d'activation et d'inhibition, à la fois intra-tumoral et périphérique, a permis de faire évoluer la 
compréhension du développement tumoral. Le développement d'un cancer et son évolution métastatique ne sont pas simplement dus à la somme des mutations génétiques d'une cellule mais résulte d'une interaction continue entre les cellules tumorales et les cellules normales de l'hôte, içi d'une patiente, représentées par les cellules immunitaires et les cellules stromales. Cette interaction continue conditionne l'histoire naturelle de la maladie cancéreuse et sa réponse au traitement. Cette compréhension doit permettre de faire changer de paradigme de traitement dans le cancer. En effet, les thérapies traditionnelles ciblent seulement les cellules tumorales afin de les détruire. De nouvelles stratégies thérapeutiques doivent également cibler le microenvironnement tumoral pour diminuer l'immunosuppression, permettant à la fois de restaurer l'immunité anti-tumorale et d'améliorer l'efficacité des thérapeutiques conventionnelles [53]. Certaines équipes commencent même à élaborer des scores basées sur l'infiltration intratumorale par des lymphocytes $\mathrm{T} \mathrm{CD} 8^{+}$ou des lymphocytes $\mathrm{T}$ régulateurs $\mathrm{FoxP}^{+}$pour guider le type de chirurgie à pratiquer dans le $\mathrm{CEO}$ [32].

\section{La chirurgie et la chimiothérapie : des immunothérapies qui s'ignorent}

Le traitement classique du CEO repose sur la chirurgie de debulking associée à une chimiothérapie systémique à base de carboplatine et de taxane. Classiquement, ces traitements sont considérés induire une immunosuppression et donc avoir un effet néfaste sur l'immunité antitumorale [54, 55]. Cependant, des données émergent pour indiquer que la chirurgie et la chimiothérapie ont un impact immunologique positif sur les patientes. Tout d'abord la chirurgie de debulking permet de réduire l'immunosuppression ce qui a permis de faire émerger le concept d'immunomodulation induite par la chirurgie de cytoréduction [20, 56-58]. L'ablation chirurgicale de la tumeur enlève des cellules sécrétant des facteurs solubles immunosuppresseurs et des lymphocytes $\mathrm{T}$ régulateurs et permet une modulation du répertoire immunologique du patient. Quelques études montrent un effet additif ou synergique entre la chirurgie et une stratégie d'immunothérapie. L'association d'une néphrectomie associée à une immunothérapie active non spécifique par IFN $\alpha$ a un meilleur pronostic que l'immunothérapie seule, permettant de suggérer un rôle adjuvant de l'ablation chirurgicale de la tumeur à une immunothérapie [59]. Les mêmes constats ont été faits dans le mélanome avec une 
immunothérapie active spécifique de type vaccination [60]. Pour certains auteurs, ces études sont des preuves indirectes de l'impact de la chirurgie de la tumeur initiale (même métastatique) sur la survie par le biais d'une immunomodulation dans le cancer [58]. On ne peut exclure cependant que le bénéfice ne soit simplement obtenu que par le biais d'une diminution de la charge tumorale, plutôt que par le biais d'une modulation de l'immunité par la chirurgie. Cependant, Raspollini et col ont évalué l'impact de la chirurgie sur l'immunité antitumorale dans le CEO [61]. Cette étude a montré que la cytoréduction chirurgicale première modifie la population des lymphocytes $\mathrm{T}$ périphériques en induisant une diminution rapide des lymphocytes $\mathrm{T}$ régulateurs $\left(\mathrm{CD} 4^{+} \mathrm{CD} 25^{+} \mathrm{FoxP} 3^{+}\right)$, augmente significativement la proportion des lymphocytes $\mathrm{T} C D 8^{+}$cytotoxiques ainsi que leur capacité à sécréter de l'IFN $\gamma$ (cytokines pro-inflammatoires bénéfiques pour la réponse anti-tumorale) et diminue significativement le taux d'interleukine 10 (cytokine immunosuppressive) dans le sang périphérique. Cette étude révèle que la chirurgie première dans le CEO diminue l'immunosuppression périphérique. Elle conforte 1'hypothèse que la chirurgie des cancers permet une amélioration de la survie des patientes par un mécanisme immunologique en diminuant l'immunotolérance.

De même, les chimiothérapies induisent souvent une lymphopénie transitoire, ce qui a conduit à penser pendant longtemps que les chimiothérapies provoquent une immunosuppression potentielle et exercent un impact négatif sur l'immunosurveillance du cancer. Cependant, les travaux de plusieurs équipes ont montré l'importance de l'immunité dans l'efficacité des chimiothérapies. Ce concept est fortement supporté par l'équipe de Zitvogel et col qui a montré l'effet immunogène des chimiothérapies ainsi que le rôle additif de l'immunité dans la réponse à la chimiothérapie [62]. Dans la chimiothérapie, plusieurs mécanismes modifient les relations entre le cancer et le système immunitaire du patient (de l'échappement à l'équilibre voire même à l'élimination selon la théorie de l'immunoéditing [63]). En effet, les agents chimiothérapeutiques peuvent restaurer ou augmenter l'expression des Ag de tumeurs [62, 64], augmenter la susceptibilité des cellules tumorales à la lyse par les effecteurs immuns [65, 66], induire la mort immunogène des cellules tumorales. Cette mort est dite immunogène lorsque la cellule tumorale exprime des signaux immunogéniques, comme le relarguage d'ATP extracellulaire, qui permettent via leur reconnaissance par des récepteurs 
membranaires (comme les Toll Like Receptor) d'augmenter la réponse immunitaire anti-tumorale [6770]. A côté de ces effets, les chimiothérapies peuvent également potentialiser leur action antitumorale en agissant sur les cellules immunitaires tolérogènes. Certaines chimiothérapies (5-Fluorouracil, Gemcitabine...) diminuent, dans des modèles animaux, la proportion des MDSC (Myeloid-Derived Duppressor Cell) dans le microenvironnement tumoral local [62, 71-73]. Dans les CEO, Napoletano et al ont montré que la chimiothérapie néoadjuvante des CEO associant carboplatine et taxol, permet de réduire l'immunosuppression en diminuant le taux de lymphocytes $\mathrm{T}$ regulateurs circulants des patientes [61]. L'action synergique des chimiothérapies avec les vaccinations mise en évidence dans le cadre d'essais cliniques constitue un autre argument de l'impact des chimiothérapies sur l'immunité $[62,74]$. Ces travaux montrent l'importance de l'immunité dans l'effet thérapeutique des différents traitements conventionnels (chirurgie et chimiothérapie) utilisés dans les CEO. Ils confirment également que le concept d'un traitement anti-cancéreux ne ciblant que la cellule tumorale est probablement dépassé et qu'il doit être élargi au traitement de la cellule tumorale en inter-relation étroite avec «son hôte ».

\section{Les stratégies d'immunothérapies évaluées dans le CEO}

Beaucoup d'espoirs sont placés dans les stratégies d'immunothérapie depuis la prise de conscience par la communauté médico-scientifique du caractère immunogène des CEO. Ainsi des études cliniques visant à prouver l'intérêt du concept d'immunothérapie dans le CEO ont été proposées en utilisant des Ac monoclonaux, le transfert adoptif de lymphocytes cytotoxiques (immunothérapie passive) ou encore des vaccinations (immunothérapie active) [75-77]. La majorité de ces études sont des études de phases I/II, avec de faibles échantillons et des critères hétérogènes d'inclusion, rendant difficile les comparaisons ainsi que l'identification de la meilleure stratégie. Des stratégies dérivées du concept des immunothérapies actives émergent également et visent à cibler le microenvironnement tumoral afin d'annuler son immunosuppression et permettre ainsi l'action des effecteurs immuns.

L'immunothérapie dite passive consiste à injecter aux patientes soit des anticorps (Ac), soit des cellules immunitaires cytotoxiques dirigées contre les cellules tumorales. Il existe un certain nombre 
d'essais cliniques qui ont utilisés différents Ac monoclonaux dirigés contre différents Ag de tumeurs des CEO comme par exemple l'oregovomab dirigé contre le Ca125 [78]. Ces immunothérapies utilisant les $\mathrm{Ac}$ (description dans le tableau $\mathrm{n}^{\circ} 3$ ) ont montré jusqu'à ce jour une bonne tolérance clinique mais des bénéfices cliniques assez mitigés, malgré une réponse immunitaire objectivée [76, 77]. L'immunothérapie adoptive utilise des cellules immunitaires de la patiente, modifiées ex vivo pour être dirigées contre les Ag de tumeur, puis réinjectées aux patientes [52]. Des essais cliniques de phase I d'immunothérapie adoptive ont été réalisés dans le CEO (table 3) avec des réponses cliniques. Cependant, l'infrastructure lourde nécessaire à la mise en place d'une immunothérapie adoptive peut être un frein à sa diffusion.

L'immunothérapie active suppose une activation des ressources immunitaires du patient pour permettre la lyse tumorale. Elle regroupe plusieurs stratégies dont la vaccination, qui peut être peptidique ou cellulaire. La vaccination peptidique a été évaluée cliniquement. Elle consiste à injecter un peptide correspondant à un Ag de tumeur comme par exemple HER2-neu [95], p53 [96] ou NYESO-1 [97, 98] ou correspondant à une protéine chimérique, résultat de la fusion de plusieurs Ag de tumeur comme par exemple le peptide chimérique HER2-neu/MAGE/FR $\alpha$ (tableau 4) [99]. Ce peptide doit déclencher une réponse immunitaire adaptive chez la patiente qui va cibler ce peptide et également les cellules tumorales puisque présentant les même Ag peptidiques. La vaccination cellulaire consiste à injecter à la patiente une cellule présentatrice d'Ag (en général une cellule dendritique), modifiée pour présenter un Ag de tumeur [100]. Des essais cliniques de vaccination cellulaire ont également été réalisés dans le CEO (tableau 4). Les essais basés sur les vaccinations ont montré une bonne tolérance clinique, la capacité à déclencher une réponse immunitaire mais malheureusement de faibles bénéfices cliniques à ce jour. Des essais se poursuivent, associant plusieurs stratégies d'immunothérapie active et passive avec des réponses thérapeutiques objectives mais toujours sur des effectifs très faibles de patientes [101]. Les essais cliniques basée sur l'immunothérapie sont difficiles à comparer, en effet les critères d'inclusion sont très variables : certains vont porter sur des patientes en récidive, d'autre sur des stades avancés avec une immunothérapie en consolidation, ou encore des patientes dont le cancer est réfractaire à la 
chimiothérapie. Ensuite, les effectifs sont souvent très faibles. Enfin, toute l'immunothérapie basée sur une manipulation ex vivo de cellules immunitaires est difficile à généraliser du fait d'une infrastructure biologique lourde pour leur mise en œuvre avec une reproductibilité parfois difficile.

\section{L'immunomodulation dans le cancer de l'ovaire}

L'immunothérapie passive ou encore les stratégies de vaccination ont jusqu'à ce jour montré des résultats thérapeutiques relativement décevants. Ces stratégies souffrent probablement d'un défaut « conceptuel ». Tout d'abord, ces essais cliniques ont enrôlé des patientes avec des stades avancés de la maladie cancéreuse ovarienne avec donc un fort climat immunosuppresseur. Ensuite, ces stratégies d'immunothérapie ciblent simplement les cellules tumorales, en négligeant de considérer l'impact du microenvironnement immunosuppresseur. Ainsi, ces stratégies d'immunothérapie doivent associer des traitements qui vont moduler ou bloquer le microenvironnement immunosuppresseur. Cette association de traitement pourra peut-être permettre d'obtenir le bénéfice clinique significatif tant espéré. Il existe déjà des approches thérapeutiques permettant de diminuer le climat tolérogène de la tumeur.

La première approche ciblant le microenvironnement tolérogène est de diminuer le développement et le recrutement au niveau tumoral des lymphocytes $\mathrm{T}$ régulateurs. Une déplétion des lymphocytes $\mathrm{T}$ régulateurs est possible par des doses faibles de cyclophosphamide [104]. De même l'utilisation de la chimiothérapie métronomique de type paclitaxel à des doses ultra-basses, non cytotoxiques permet de diminuer la formation de lymphocytes $\mathrm{T}$ régulateurs [105]. L'utilisation d'une protéine de fusion associant l'interleukine 2 (reconnue par le CD25 porté par le lymphocyte T régulateur) à la toxine diphtérique (Ontak®) a également permis une déplétion des lymphocytes T régulateurs circulant dans le cancer de l'ovaire (NCT00880360, clinicaltrial.gov) [105]. Cependant il n'est pas démontré que cette déplétion des lymphocytes $\mathrm{T}$ régulateurs systémiques survient également au niveau du site tumoral et permet une amélioration de la survie [106]. 
Une autre stratégie ciblant le microenvironnement tumoral immunosuppresseur est de bloquer les récepteurs membranaires de type «checkpoint » dont l'engagement induit l'immunosuppression. Il existe deux récepteurs clés qui ont récemment fait beaucoup de bruit dans le monde médicoscientifique en terme de succès thérapeutique. Il s'agit de CTLA-4 (Cytotoxic TLymphocyte Antigen 4) et de PD-1. CTLA-4 est un récepteur exprimé par les lymphocytes T suite à l'engagement du recepteur $\mathrm{T}$ par l'Ag, qui va dans les situations physiologiques «éteindre la réaction » immunitaire. Le blocage de CTLA-4 par un Ac bloquant (Ipilumimab, Yervoy®, BristolMyers-Squibb) augmente la réponse lymphocytaire T spécifique d'Ag. L'immunothérapie basée sur l'ipilumimab a été évaluée dans le CEO avec des réponses thérapeutiques objectives chez des patientes préalablement vaccinées à l'aide de cellules tumorales autologues irradiées [107, 108]. La réponse tumorale à cette stratégie de vaccination associée à l'ipilumimab est corrélée au ratio lymphocyte $\mathrm{T}$ CD8/T régulateur intratumoral. L'ipilumimab a été approuvé par la FDA (Food and Drug Administration) dans le mélanome. Il s'agit de la première thérapie bloquant un «checkpoint» d'induction de l'immunosuppression approuvée en thérapeutique clinique. La seconde révolution dans le domaine concerne PD-1. PD-1 est exprimé par les TIL. L'engagement de PD-1 par PD-L1, exprimé par les cellules tumorales, est un puissant mécanisme d'immunosuppression, supprimant la réponse immunitaire des lymphocytes T. L'expression de PD-L1 est un facteur indépendant de mauvais pronostic dans le CEO $[22,36]$. Des Ac thérapeutiques anti-PD-1 ont été développés avec un bénéfice clinique pour 20 à $25 \%$ de patients traités pour un cancer du poumon, du rein ou un mélanome (nivolumab, BMS-936558, Bristol-Myers-Squibb) [109]. Un Ac anti-PD-L1 (BMS-936559) a été évalué chez 17 patientes porteuses de CEO avec une patiente présentant une réponse objective [110]. De nouveaux essais cliniques sont en cours pour évaluer ces stratégies de blocage du couple PD-1/PDL1 afin notamment d'identifier des biomarqueurs prédictifs de réponse [111].

Enfin, une troisième stratégie ciblant le microenvironnement tumoral immunosuppresseur est de bloquer les molécules solubles inhibitrices. Des essais cliniques sont ainsi en train d'évaluer l'inhibition d'IDO, enzyme puissamment immunosuppressive, dans le CEO après la première ligne de chimiothérapie (NCT01685255, clinicaltrial.gov). D’autres molécules immunosuppressives comme la 
prostaglandine E2 pourrait faire l'objet d'essai clinique. En effet, il existe des molécules de grade clinique, comme le Célébrex ${ }^{\circledR}$ (Pfizer), capable d'inhiber l'enzyme COX-2, impliquée dans la synthèse de la prostaglandine E2.

\section{Conclusion}

L'immunologie occupe une place prépondérante dans le développement du cancer de l'ovaire. L'immunité antitumorale conditionne de manière majeure le pronostic de la maladie cancéreuse. Les cellules immunitaires, au sein d'un microenvironnement tumoral complexe, combattent et entretiennent en même temps le développement du cancer, poussant à modifier le paradigme de traitement anti-cancéreux. Les drogues anti-tumorales ne doivent pas simplement cibler les cellules tumorales mais tenir compte également de «l'hôte», de ses cellules immunitaires dont la fonctionnalité conditionne une partie du succès thérapeutique. L'immunothérapie, après des essais cliniques peu concluants, proposent aujourd'hui de nouvelles perspectives très prometteuses quand elle s'intéresse au microenvironnement immunosuppresseur. 


\section{Références}

[1] Jemal A, Siegel R, Ward E, Hao Y, Xu J, Thun MJ. Cancer statistics, 2009. CA Cancer J Clin 2009;59: 225-49.

[2] Pfisterer J, Ledermann JA. Management of platinum-sensitive recurrent ovarian cancer. Semin Oncol 2006;33: S12-6.

[3] Hoskins P, Vergote I, Cervantes A, Tu D, Stuart G, Zola P, Poveda A, Provencher D, Katsaros D, Ojeda B, Ghatage P, Grimshaw R, Casado A, Elit L, Mendiola C, Sugimoto A, D'Hondt V, Oza A, Germa $J R$, Roy M, Brotto L, Chen D, Eisenhauer EA. Advanced ovarian cancer: phase III randomized study of sequential cisplatin-topotecan and carboplatin-paclitaxel vs carboplatin-paclitaxel. J Natl Cancer Inst 2010;102: 1547-56.

[4] Rafii A, Stoeckle E, Jean-Laurent M, Ferron G, Morice P, Houvenaeghel G, Lecuru F, Leblanc E, Querleu D. Multi-center evaluation of post-operative morbidity and mortality after optimal cytoreductive surgery for advanced ovarian cancer. PLoS One 2012;7: e39415.

[5] Vergote I, Trope CG, Amant F, Kristensen GB, Ehlen T, Johnson N, Verheijen RH, van der Burg ME, Lacave AJ, Panici PB, Kenter GG, Casado A, Mendiola C, Coens C, Verleye L, Stuart GC, Pecorelli S, Reed NS. Neoadjuvant chemotherapy or primary surgery in stage IIIC or IV ovarian cancer. N Engl J Med 2010;363: 943-53.

[6] Perren TJ, Swart AM, Pfisterer J, Ledermann JA, Pujade-Lauraine E, Kristensen G, Carey MS, Beale P, Cervantes A, Kurzeder C, du Bois A, Sehouli J, Kimmig R, Stahle A, Collinson F, Essapen S, Gourley C, Lortholary A, Selle F, Mirza MR, Leminen A, Plante M, Stark D, Qian W, Parmar MK, Oza AM. A phase 3 trial of bevacizumab in ovarian cancer. N Engl J Med 2011;365: 2484-96.

[7] Metzger-Filho O, Procter M, de Azambuja E, Leyland-Jones B, Gelber RD, Dowsett M, Loi S, Saini KS, Cameron D, Untch M, Smith I, Gianni L, Baselga J, Jackisch C, Bell R, Sotiriou C, Viale G, Piccart-Gebhart M. Magnitude of Trastuzumab Benefit in Patients With HER2-Positive, Invasive Lobular Breast Carcinoma: Results From the HERA Trial. J Clin Oncol 2013.

[8] O'Brien SG, Guilhot F, Larson RA, Gathmann I, Baccarani M, Cervantes F, Cornelissen JJ, Fischer T, Hochhaus A, Hughes T, Lechner K, Nielsen JL, Rousselot P, Reiffers J, Saglio G, Shepherd J, Simonsson B, Gratwohl A, Goldman JM, Kantarjian H, Taylor K, Verhoef G, Bolton AE, Capdeville R, Druker BJ. Imatinib compared with interferon and low-dose cytarabine for newly diagnosed chronicphase chronic myeloid leukemia. N Engl J Med 2003;348: 994-1004.

[9] Llovet JM, Ricci S, Mazzaferro V, Hilgard P, Gane E, Blanc JF, de Oliveira AC, Santoro A, Raoul JL, Forner A, Schwartz M, Porta C, Zeuzem S, Bolondi L, Greten TF, Galle PR, Seitz JF, Borbath I, Haussinger D, Giannaris T, Shan M, Moscovici M, Voliotis D, Bruix J. Sorafenib in advanced hepatocellular carcinoma. N Engl J Med 2008;359: 378-90.

[10] Goodell V, Salazar LG, Urban N, Drescher CW, Gray H, Swensen RE, McIntosh MW, Disis ML. Antibody immunity to the p53 oncogenic protein is a prognostic indicator in ovarian cancer. J Clin Oncol 2006;24: 762-8.

[11] Schlienger K, Chu CS, Woo EY, Rivers PM, Toll AJ, Hudson B, Maus MV, Riley JL, Choi Y, Coukos G, Kaiser LR, Rubin SC, Levine BL, Carroll RG, June CH. TRANCE- and CD40 ligand-matured dendritic cells reveal $\mathrm{MHC}$ class I-restricted T cells specific for autologous tumor in late-stage ovarian cancer patients. Clin Cancer Res 2003;9: 1517-27.

[12] Ioannides CG, Fisk B, Fan D, Biddison WE, Wharton JT, O'Brian CA. Cytotoxic T cells isolated from ovarian malignant ascites recognize a peptide derived from the HER-2/neu proto-oncogene. Cell Immunol 1993;151: 225-34.

[13] Chauhan SC, Singh AP, Ruiz F, Johansson SL, Jain M, Smith LM, Moniaux N, Batra SK. Aberrant expression of MUC4 in ovarian carcinoma: diagnostic significance alone and in combination with MUC1 and MUC16 (CA125). Mod Pathol 2006;19: 1386-94.

[14] Peoples GE, Anderson BW, Fisk B, Kudelka AP, Wharton JT, loannides CG. Ovarian cancerassociated lymphocyte recognition of folate binding protein peptides. Ann Surg Oncol 1998;5: 74350. 
[15] Runz S, Keller S, Rupp C, Stoeck A, Issa Y, Koensgen D, Mustea A, Sehouli J, Kristiansen G, Altevogt P. Malignant ascites-derived exosomes of ovarian carcinoma patients contain CD24 and EpCAM. Gynecol Oncol 2007;107: 563-71.

[16] Zhang S, Zhou X, Yu H, Yu Y. Expression of tumor-specific antigen MAGE, GAGE and BAGE in ovarian cancer tissues and cell lines. BMC Cancer 2010;10: 163.

[17] Zhang L, Conejo-Garcia JR, Katsaros D, Gimotty PA, Massobrio M, Regnani G, Makrigiannakis A, Gray H, Schlienger K, Liebman MN, Rubin SC, Coukos G. Intratumoral T cells, recurrence, and survival in epithelial ovarian cancer. N Engl J Med 2003;348: 203-13.

[18] Garzetti GG, Cignitti M, Ciavattini A, Fabris N, Romanini C. Natural killer cell activity and progression-free survival in ovarian cancer. Gynecol Obstet Invest 1993;35: 118-20.

[19] Thedrez A, Lavoue V, Dessarthe B, Daniel P, Henno S, Jaffre I, Leveque J, Catros V, Cabillic F. A quantitative deficiency in peripheral blood Vgamma9Vdelta2 cells is a negative prognostic biomarker in ovarian cancer patients. PLoS One 2013: [Epud ahead of print].

[20] Raspollini MR, Castiglione F, Rossi Degl'innocenti D, Amunni G, Villanucci A, Garbini F, Baroni G, Taddei GL. Tumour-infiltrating gamma/delta T-lymphocytes are correlated with a brief diseasefree interval in advanced ovarian serous carcinoma. Ann Oncol 2005;16: 590-6.

[21] Sato E, Olson SH, Ahn J, Bundy B, Nishikawa H, Qian F, Jungbluth AA, Frosina D, Gnjatic S, Ambrosone C, Kepner J, Odunsi T, Ritter G, Lele S, Chen YT, Ohtani H, Old LJ, Odunsi K. Intraepithelial CD8+ tumor-infiltrating lymphocytes and a high CD8+/regulatory $\mathrm{T}$ cell ratio are associated with favorable prognosis in ovarian cancer. Proc Natl Acad Sci U S A 2005;102: 18538-43.

[22] Hamanishi J, Mandai M, Iwasaki M, Okazaki T, Tanaka Y, Yamaguchi K, Higuchi T, Yagi H, Takakura K, Minato N, Honjo T, Fujii S. Programmed cell death 1 ligand 1 and tumor-infiltrating CD8+ T lymphocytes are prognostic factors of human ovarian cancer. Proc Natl Acad Sci U S A 2007;104: 3360-5.

[23] Clarke B, Tinker AV, Lee CH, Subramanian S, van de Rijn M, Turbin D, Kalloger S, Han G, Ceballos K, Cadungog MG, Huntsman DG, Coukos G, Gilks CB. Intraepithelial T cells and prognosis in ovarian carcinoma: novel associations with stage, tumor type, and BRCA1 loss. Mod Pathol 2009;22: 393-402.

[24] Shah CA, Allison KH, Garcia RL, Gray HJ, Goff BA, Swisher EM. Intratumoral T cells, tumorassociated macrophages, and regulatory $T$ cells: association with p53 mutations, circulating tumor DNA and survival in women with ovarian cancer. Gynecol Oncol 2008;109: 215-9.

[25] Tomsova M, Melichar B, Sedlakova I, Steiner I. Prognostic significance of CD3+ tumorinfiltrating lymphocytes in ovarian carcinoma. Gynecol Oncol 2008;108: 415-20.

[26] Callahan MJ, Nagymanyoki Z, Bonome T, Johnson ME, Litkouhi B, Sullivan EH, Hirsch MS, Matulonis UA, Liu J, Birrer MJ, Berkowitz RS, Mok SC. Increased HLA-DMB expression in the tumor epithelium is associated with increased CTL infiltration and improved prognosis in advanced-stage serous ovarian cancer. Clin Cancer Res 2008;14: 7667-73.

[27] Han LY, Fletcher MS, Urbauer DL, Mueller P, Landen CN, Kamat AA, Lin YG, Merritt WM, Spannuth WA, Deavers MT, De Geest K, Gershenson DM, Lutgendorf SK, Ferrone S, Sood AK. HLA class I antigen processing machinery component expression and intratumoral T-Cell infiltrate as independent prognostic markers in ovarian carcinoma. Clin Cancer Res 2008;14: 3372-9.

[28] Stumpf $M$, Hasenburg A, Riener MO, Jutting U, Wang C, Shen $Y$, Orlowska-Volk M, Fisch P, Wang Z, Gitsch G, Werner M, Lassmann S. Intraepithelial CD8-positive T lymphocytes predict survival for patients with serous stage III ovarian carcinomas: relevance of clonal selection of T lymphocytes. Br J Cancer 2009;101: 1513-21.

[29] Leffers N, Gooden MJ, de Jong RA, Hoogeboom BN, ten Hoor KA, Hollema H, Boezen HM, van der Zee AG, Daemen T, Nijman HW. Prognostic significance of tumor-infiltrating T-lymphocytes in primary and metastatic lesions of advanced stage ovarian cancer. Cancer Immunol Immunother 2009;58: 449-59. 
[30] Leffers N, Fehrmann RS, Gooden MJ, Schulze UR, Ten Hoor KA, Hollema H, Boezen HM, Daemen T, de Jong S, Nijman HW, van der Zee AG. Identification of genes and pathways associated with cytotoxic T lymphocyte infiltration of serous ovarian cancer. Br J Cancer 2010;103: 685-92.

[31] Milne K, Kobel M, Kalloger SE, Barnes RO, Gao D, Gilks CB, Watson PH, Nelson BH. Systematic analysis of immune infiltrates in high-grade serous ovarian cancer reveals CD20, FoxP3 and TIA-1 as positive prognostic factors. PLoS One 2009;4: e6412.

[32] Adams SF, Levine DA, Cadungog MG, Hammond R, Facciabene A, Olvera N, Rubin SC, Boyd J, Gimotty PA, Coukos G. Intraepithelial T cells and tumor proliferation: impact on the benefit from surgical cytoreduction in advanced serous ovarian cancer. Cancer 2009;115: 2891-902.

[33] Kryczek I, Banerjee M, Cheng P, Vatan L, Szeliga W, Wei S, Huang E, Finlayson E, Simeone D, Welling TH, Chang A, Coukos G, Liu R, Zou W. Phenotype, distribution, generation, and functional and clinical relevance of Th17 cells in the human tumor environments. Blood 2009;114: 1141-9.

[34] Schreiber RD, Old LJ, Smyth MJ. Cancer immunoediting: integrating immunity's roles in cancer suppression and promotion. Science 2011;331: 1565-70.

[35] MacKie RM, Reid R, Junor B. Fatal melanoma transferred in a donated kidney 16 years after melanoma surgery. N Engl J Med 2003;348: 567-8.

[36] Abiko K, Mandai M, Hamanishi J, Yoshioka Y, Matsumura N, Baba T, Yamaguchi K, Murakami R, Yamamoto A, Kharma B, Kosaka K, Konishi I. PD-L1 on Tumor Cells Is Induced in Ascites and Promotes Peritoneal Dissemination of Ovarian Cancer through CTL Dysfunction. Clin Cancer Res 2013;19: 1363-74.

[37] Matsuzaki J, Gnjatic S, Mhawech-Fauceglia P, Beck A, Miller A, Tsuji T, Eppolito C, Qian F, Lele $S$, Shrikant $P$, Old LJ, Odunsi K. Tumor-infiltrating NY-ESO-1-specific CD8+ T cells are negatively regulated by LAG-3 and PD-1 in human ovarian cancer. Proc Natl Acad Sci U S A 2010;107: 7875-80.

[38] Okamoto A, Nikaido T, Ochiai K, Takakura S, Saito M, Aoki Y, Ishii N, Yanaihara N, Yamada K, Takikawa O, Kawaguchi R, Isonishi S, Tanaka T, Urashima M. Indoleamine 2,3-dioxygenase serves as a marker of poor prognosis in gene expression profiles of serous ovarian cancer cells. Clin Cancer Res 2005;11: 6030-9.

[39] Inaba $T$, Ino K, Kajiyama H, Yamamoto E, Shibata $K$, Nawa A, Nagasaka T, Akimoto $H$, Takikawa O, Kikkawa F. Role of the immunosuppressive enzyme indoleamine 2,3-dioxygenase in the progression of ovarian carcinoma. Gynecol Oncol 2009;115: 185-92.

[40] Mellor AL, Munn DH. Creating immune privilege: active local suppression that benefits friends, but protects foes. Nat Rev Immunol 2008;8: 74-80.

[41] Nonaka H, Saga Y, Fujiwara H, Akimoto H, Yamada A, Kagawa S, Takei Y, Machida S, Takikawa $\mathrm{O}$, Suzuki M. Indoleamine 2,3-dioxygenase promotes peritoneal dissemination of ovarian cancer through inhibition of natural killercell function and angiogenesis promotion. Int J Oncol 2011;38: 11320.

[42] Qian F, Villella J, Wallace PK, Mhawech-Fauceglia P, Tario JD, Jr., Andrews C, Matsuzaki J, Valmori D, Ayyoub M, Frederick PJ, Beck A, Liao J, Cheney R, Moysich K, Lele S, Shrikant P, Old LJ, Odunsi K. Efficacy of levo-1-methyl tryptophan and dextro-1-methyl tryptophan in reversing indoleamine-2,3-dioxygenase-mediated arrest of $\mathrm{T}$-cell proliferation in human epithelial ovarian cancer. Cancer Res 2009;69: 5498-504.

[43] Bishara S, Griffin M, Cargill A, Bali A, Gore ME, Kaye SB, Shepherd JH, Van Trappen PO. Pretreatment white blood cell subtypes as prognostic indicators in ovarian cancer. Eur J Obstet Gynecol Reprod Biol 2008;138: 71-5.

[44] Cho H, Hur HW, Kim SW, Kim SH, Kim JH, Kim YT, Lee K. Pre-treatment neutrophil to lymphocyte ratio is elevated in epithelial ovarian cancer and predicts survival after treatment. Cancer Immunol Immunother 2009;58: 15-23.

[45] Curiel TJ, Coukos G, Zou L, Alvarez X, Cheng P, Mottram P, Evdemon-Hogan M, Conejo-Garcia JR, Zhang L, Burow M, Zhu Y, Wei S, Kryczek I, Daniel B, Gordon A, Myers L, Lackner A, Disis ML, 
Knutson KL, Chen L, Zou W. Specific recruitment of regulatory T cells in ovarian carcinoma fosters immune privilege and predicts reduced survival. Nat Med 2004;10: 942-9.

[46] Wolf D, Wolf AM, Rumpold H, Fiegl H, Zeimet AG, Muller-Holzner E, Deibl M, Gastl G, Gunsilius $\mathrm{E}$, Marth $\mathrm{C}$. The expression of the regulatory T cell-specific forkhead box transcription factor FoxP3 is associated with poor prognosis in ovarian cancer. Clin Cancer Res 2005;11: 8326-31.

[47] Dong HP, Elstrand MB, Holth A, Silins I, Berner A, Trope CG, Davidson B, Risberg B. NK- and Bcell infiltration correlates with worse outcome in metastatic ovarian carcinoma. Am J Clin Pathol 2006;125: 451-8.

[48] Kryczek I, Wei S, Zhu G, Myers L, Mottram P, Cheng P, Chen L, Coukos G, Zou W. Relationship between $\mathrm{B} 7-\mathrm{H} 4$, regulatory $\mathrm{T}$ cells, and patient outcome in human ovarian carcinoma. Cancer Res 2007;67: 8900-5.

[49] Buckanovich RJ, Facciabene A, Kim S, Benencia F, Sasaroli D, Balint K, Katsaros D, O'BrienJenkins A, Gimotty PA, Coukos G. Endothelin B receptor mediates the endothelial barrier to $T$ cell homing to tumors and disables immune therapy. Nat Med 2008;14: 28-36.

[50] Labidi-Galy SI, Sisirak V, Meeus P, Gobert M, Treilleux I, Bajard A, Combes JD, Faget J, Mithieux F, Cassignol A, Tredan O, Durand I, Menetrier-Caux C, Caux C, Blay JY, Ray-Coquard I, Bendriss-Vermare N. Quantitative and functional alterations of plasmacytoid dendritic cells contribute to immune tolerance in ovarian cancer. Cancer Res 2011;71: 5423-34.

[51] Conrad C, Gregorio J, Wang YH, Ito T, Meller S, Hanabuchi S, Anderson S, Atkinson N, Ramirez PT, Liu YJ, Freedman R, Gilliet M. Plasmacytoid dendritic cells promote immunosuppression in ovarian cancer via ICOS costimulation of Foxp3(+) T-regulatory cells. Cancer Res 2012;72: 5240-9.

[52] Lavoue V, Cabillic F, Toutirais O, Thedrez A, Dessarthe B, de La Pintiere CT, Daniel P, Foucher F, Bauville E, Henno S, Burtin F, Bansard JY, Leveque J, Catros V, Bouet-Toussaint F. Sensitization of ovarian carcinoma cells with zoledronate restores the cytotoxic capacity of Vgamma9Vdelta2 $\mathrm{T}$ cells impaired by the prostaglandin E2 immunosuppressive factor: implications for immunotherapy. Int J Cancer 2012;131: E449-62.

[53] Emens LA, Silverstein SC, Khleif S, Marincola FM, Galon J. Toward integrative cancer immunotherapy: targeting the tumor microenvironment. J Transl Med 2012;10: 70.

[54] Brune IB, Wilke W, Hensler T, Holzmann B, Siewert JR. Downregulation of T helper type 1 immune response and altered pro-inflammatory and anti-inflammatory $\mathrm{T}$ cell cytokine balance following conventional but not laparoscopic surgery. Am J Surg 1999;177: 55-60.

[55] Hensler T, Hecker H, Heeg K, Heidecke CD, Bartels H, Barthlen W, Wagner H, Siewert JR, Holzmann B. Distinct mechanisms of immunosuppression as a consequence of major surgery. Infect Immun 1997;65: 2283-91.

[56] Baumgartner JM, McCarter MD. Suppressing the suppressor: Role of immunosuppressive regulatory T cells in cancer surgery. Surgery 2009;145: 345-50.

[57] Bubenik J, Simova J. Minimal residual disease as the target for immunotherapy and gene therapy of cancer (review). Oncol Rep 2005;14: 1377-80.

[58] Gonzalez HD, Figueras J. Effect of surgical resection of metastatic disease on immune tolerance to cancer. How a systemic disease could be controlled by a local therapy. Clin Transl Oncol 2007;9: 571-7.

[59] Flanigan RC, Salmon SE, Blumenstein BA, Bearman SI, Roy V, McGrath PC, Caton JR, Jr., Munshi N, Crawford ED. Nephrectomy followed by interferon alfa-2b compared with interferon alfa2b alone for metastatic renal-cell cancer. N Engl J Med 2001;345: 1655-9.

[60] Tagawa ST, Cheung E, Banta W, Gee C, Weber JS. Survival analysis after resection of metastatic disease followed by peptide vaccines in patients with Stage IV melanoma. Cancer 2006;106: 1353-7.

[61] Napoletano C, Bellati F, Landi R, Pauselli S, Marchetti C, Visconti V, Sale P, Liberati M, Rughetti A, Frati L, Panici PB, Nuti M. Ovarian cancer cytoreduction induces changes in $T$ cell population subsets reducing immunosuppression. J Cell Mol Med 2010;14: 2748-59. 
[62] Zitvogel L, Kepp O, Kroemer G. Immune parameters affecting the efficacy of chemotherapeutic regimens. Nat Rev Clin Oncol 2011;8: 151-60.

[63] Dunn GP, Old LJ, Schreiber RD. The three Es of cancer immunoediting. Annu Rev Immunol 2004;22: 329-60.

[64] Reits EA, Hodge JW, Herberts CA, Groothuis TA, Chakraborty M, Wansley EK, Camphausen K, Luiten RM, de Ru AH, Neijssen J, Griekspoor A, Mesman E, Verreck FA, Spits H, Schlom J, van Veelen $P$, Neefjes JJ. Radiation modulates the peptide repertoire, enhances MHC class I expression, and induces successful antitumor immunotherapy. J Exp Med 2006;203: 1259-71.

[65] Raulet DH, Guerra N. Oncogenic stress sensed by the immune system: role of natural killer cell receptors. Nat Rev Immunol 2009;9: 568-80.

[66] van der Most RG, Currie AJ, Cleaver AL, Salmons J, Nowak AK, Mahendran S, Larma I, Prosser A, Robinson BW, Smyth MJ, Scalzo AA, Degli-Esposti MA, Lake RA. Cyclophosphamide chemotherapy sensitizes tumor cells to TRAIL-dependent CD8 T cell-mediated immune attack resulting in suppression of tumor growth. PLoS One 2009;4: e6982.

[67] Ghiringhelli F, Apetoh L, Tesniere A, Aymeric L, Ma Y, Ortiz C, Vermaelen K, Panaretakis T, Mignot G, Ullrich E, Perfettini JL, Schlemmer F, Tasdemir E, Uhl M, Genin P, Civas A, Ryffel B, Kanellopoulos J, Tschopp J, Andre F, Lidereau R, McLaughlin NM, Haynes NM, Smyth MJ, Kroemer G, Zitvogel L. Activation of the NLRP3 inflammasome in dendritic cells induces IL-1beta-dependent adaptive immunity against tumors. Nat Med 2009;15: 1170-8.

[68] Apetoh L, Ghiringhelli F, Tesniere A, Obeid M, Ortiz C, Criollo A, Mignot G, Maiuri MC, Ullrich E, Saulnier P, Yang H, Amigorena S, Ryffel B, Barrat FJ, Saftig P, Levi F, Lidereau R, Nogues C, Mira JP, Chompret A, Joulin V, Clavel-Chapelon F, Bourhis J, Andre F, Delaloge S, Tursz T, Kroemer G, Zitvogel L. Toll-like receptor 4-dependent contribution of the immune system to anticancer chemotherapy and radiotherapy. Nat Med 2007;13: 1050-9.

[69] Casares N, Pequignot MO, Tesniere A, Ghiringhelli F, Roux S, Chaput N, Schmitt E, Hamai A, Hervas-Stubbs S, Obeid M, Coutant F, Metivier D, Pichard E, Aucouturier P, Pierron G, Garrido C, Zitvogel L, Kroemer G. Caspase-dependent immunogenicity of doxorubicin-induced tumor cell death. J Exp Med 2005;202: 1691-701.

[70] Zitvogel L, Apetoh L, Ghiringhelli F, Andre F, Tesniere A, Kroemer G. The anticancer immune response: indispensable for therapeutic success? J Clin Invest 2008;118: 1991-2001.

[71] Vincent J, Mignot G, Chalmin F, Ladoire S, Bruchard M, Chevriaux A, Martin F, Apetoh L, Rebe C, Ghiringhelli F. 5-Fluorouracil selectively kills tumor-associated myeloid-derived suppressor cells resulting in enhanced T cell-dependent antitumor immunity. Cancer Res 2010;70: 3052-61.

[72] Movahedi K, Guilliams M, Van den Bossche J, Van den Bergh R, Gysemans C, Beschin A, De Baetselier P, Van Ginderachter JA. Identification of discrete tumor-induced myeloid-derived suppressor cell subpopulations with distinct T cell-suppressive activity. Blood 2008;111: 4233-44.

[73] Suzuki E, Kapoor V, Jassar AS, Kaiser LR, Albelda SM. Gemcitabine selectively eliminates splenic $\mathrm{Gr}-1+/ \mathrm{CD} 11 \mathrm{~b}+$ myeloid suppressor cells in tumor-bearing animals and enhances antitumor immune activity. Clin Cancer Res 2005;11: 6713-21.

[74] Chiappori AA, Soliman H, Janssen WE, Antonia SJ, Gabrilovich DI. INGN-225: a dendritic cellbased p53 vaccine (Ad.p53-DC) in small cell lung cancer: observed association between immune response and enhanced chemotherapy effect. Expert Opin Biol Ther 2010;10: 983-91.

[75] Kandalaft LE, Powell DJ, Jr., Singh N, Coukos G. Immunotherapy for ovarian cancer: what's next? J Clin Oncol 2011;29: 925-33.

[76] Preston CC, Goode EL, Hartmann LC, Kalli KR, Knutson KL. Immunity and immune suppression in human ovarian cancer. Immunotherapy 2011;3: 539-56.

[77] Leffers N, Daemen T, Helfrich W, Boezen HM, Cohlen BJ, Melief K, Nijman HW. Antigenspecific active immunotherapy for ovarian cancer. Cochrane Database Syst Rev 2010: CD007287.

[78] Frederick PJ, Straughn JM, Jr., Alvarez RD, Buchsbaum DJ. Preclinical studies and clinical utilization of monoclonal antibodies in epithelial ovarian cancer. Gynecol Oncol 2009;113: 384-90. 
[79] Berek J, Taylor P, McGuire W, Smith LM, Schultes B, Nicodemus CF. Oregovomab maintenance monoimmunotherapy does not improve outcomes in advanced ovarian cancer. J Clin Oncol 2009;27: 418-25.

[80] Ehlen TG, Hoskins PJ, Miller D, Whiteside TL, Nicodemus CF, Schultes BC, Swenerton KD. A pilot phase 2 study of oregovomab murine monoclonal antibody to CA125 as an immunotherapeutic agent for recurrent ovarian cancer. Int J Gynecol Cancer 2005;15: 1023-34.

[81] Reinartz S, Kohler S, Schlebusch H, Krista K, Giffels P, Renke K, Huober J, Mobus V, Kreienberg $R$, DuBois A, Sabbatini P, Wagner U. Vaccination of patients with advanced ovarian carcinoma with the anti-idiotype ACA125: immunological response and survival (phase Ib/II). Clin Cancer Res 2004;10: 1580-7.

[82] Bookman MA, Darcy KM, Clarke-Pearson D, Boothby RA, Horowitz IR. Evaluation of monoclonal humanized anti-HER2 antibody, trastuzumab, in patients with recurrent or refractory ovarian or primary peritoneal carcinoma with overexpression of HER2: a phase II trial of the Gynecologic Oncology Group. J Clin Oncol 2003;21: 283-90.

[83] Gordon MS, Matei D, Aghajanian C, Matulonis UA, Brewer M, Fleming GF, Hainsworth JD, Garcia AA, Pegram MD, Schilder RJ, Cohn DE, Roman L, Derynck MK, Ng K, Lyons B, Allison DE, Eberhard DA, Pham TQ, Dere RC, Karlan BY. Clinical activity of pertuzumab (rhuMAb 2C4), a HER dimerization inhibitor, in advanced ovarian cancer: potential predictive relationship with tumor HER2 activation status. J Clin Oncol 2006;24: 4324-32.

[84] Makhija S, Amler LC, Glenn D, Ueland FR, Gold MA, Dizon DS, Paton V, Lin CY, Januario T, Ng K, Strauss A, Kelsey S, Sliwkowski MX, Matulonis U. Clinical activity of gemcitabine plus pertuzumab in platinum-resistant ovarian cancer, fallopian tube cancer, or primary peritoneal cancer. J Clin Oncol 2010;28: 1215-23.

[85] Langdon SP, Faratian D, Nagumo Y, Mullen P, Harrison DJ. Pertuzumab for the treatment of ovarian cancer. Expert Opin Biol Ther 2010;10: 1113-20.

[86] Konner JA, Bell-McGuinn KM, Sabbatini P, Hensley ML, Tew WP, Pandit-Taskar N, Vander Els N, Phillips MD, Schweizer C, Weil SC, Larson SM, Old LJ. Farletuzumab, a humanized monoclonal antibody against folate receptor alpha, in epithelial ovarian cancer: a phase I study. Clin Cancer Res 2010;16: 5288-95.

[87] Spannuth WA, Sood AK, Coleman RL. Farletuzumab in epithelial ovarian carcinoma. Expert Opin Biol Ther 2010;10: 431-7.

[88] Burges A, Wimberger P, Kumper C, Gorbounova V, Sommer H, Schmalfeldt B, Pfisterer J, Lichinitser M, Makhson A, Moiseyenko V, Lahr A, Schulze E, Jager M, Strohlein MA, Heiss MM, Gottwald T, Lindhofer $\mathrm{H}$, Kimmig R. Effective relief of malignant ascites in patients with advanced ovarian cancer by a trifunctional anti-EpCAM $\mathrm{x}$ anti-CD3 antibody: a phase $\mathrm{I} / \mathrm{II}$ study. Clin Cancer Res 2007;13: 3899-905.

[89] Heiss MM, Murawa P, Koralewski P, Kutarska E, Kolesnik OO, Ivanchenko VV, Dudnichenko AS, Aleknaviciene B, Razbadauskas A, Gore M, Ganea-Motan E, Ciuleanu T, Wimberger P, Schmittel A, Schmalfeldt B, Burges A, Bokemeyer C, Lindhofer H, Lahr A, Parsons SL. The trifunctional antibody catumaxomab for the treatment of malignant ascites due to epithelial cancer: Results of a prospective randomized phase II/III trial. Int J Cancer 2010;127: 2209-21.

[90] Aoki Y, Takakuwa K, Kodama S, Tanaka K, Takahashi M, Tokunaga A, Takahashi T. Use of adoptive transfer of tumor-infiltrating lymphocytes alone or in combination with cisplatin-containing chemotherapy in patients with epithelial ovarian cancer. Cancer Res 1991;51: 1934-9.

[91] Freedman RS, Edwards CL, Kavanagh JJ, Kudelka AP, Katz RL, Carrasco CH, Atkinson EN, Scott W, Tomasovic B, Templin S, et al. Intraperitoneal adoptive immunotherapy of ovarian carcinoma with tumor-infiltrating lymphocytes and low-dose recombinant interleukin-2: a pilot trial. J Immunother Emphasis Tumor Immunol 1994;16: 198-210. 
[92] Fujita K, Ikarashi H, Takakuwa K, Kodama S, Tokunaga A, Takahashi T, Tanaka K. Prolonged disease-free period in patients with advanced epithelial ovarian cancer after adoptive transfer of tumor-infiltrating lymphocytes. Clin Cancer Res 1995;1: 501-7.

[93] Kershaw MH, Westwood JA, Parker LL, Wang G, Eshhar Z, Mavroukakis SA, White DE, Wunderlich JR, Canevari S, Rogers-Freezer L, Chen CC, Yang JC, Rosenberg SA, Hwu P. A phase I study on adoptive immunotherapy using gene-modified T cells for ovarian cancer. Clin Cancer Res 2006;12: 6106-15.

[94] Dobrzanski MJ, Rewers-Felkins KA, Quinlin IS, Samad KA, Phillips CA, Robinson W, Dobrzanski DJ, Wright SE. Autologous MUC1-specific Th1 effector cell immunotherapy induces differential levels of systemic TReg cell subpopulations that result in increased ovarian cancer patient survival. Clin Immunol 2009;133: 333-52.

[95] Disis ML, Gooley TA, Rinn K, Davis D, Piepkorn M, Cheever MA, Knutson KL, Schiffman K. Generation of T-cell immunity to the HER-2/neu protein after active immunization with HER-2/neu peptide-based vaccines. J Clin Oncol 2002;20: 2624-32.

[96] Leffers N, Lambeck AJ, Gooden MJ, Hoogeboom BN, Wolf R, Hamming IE, Hepkema BG, Willemse PH, Molmans BH, Hollema H, Drijfhout JW, Sluiter WJ, Valentijn AR, Fathers LM, Oostendorp J, van der Zee AG, Melief CJ, van der Burg SH, Daemen T, Nijman HW. Immunization with a P53 synthetic long peptide vaccine induces P53-specific immune responses in ovarian cancer patients, a phase II trial. Int J Cancer 2009;125: 2104-13.

[97] Diefenbach CS, Gnjatic S, Sabbatini P, Aghajanian C, Hensley ML, Spriggs DR, lasonos A, Lee H, Dupont B, Pezzulli S, Jungbluth AA, Old L, Dupont J. Safety and immunogenicity study of NY-ESO-1b peptide and montanide ISA-51 vaccination of patients with epithelial ovarian cancer in high-risk first remission. Clin Cancer Res 2008;14: 2740-8.

[98] Odunsi K, Qian F, Matsuzaki J, Mhawech-Fauceglia P, Andrews C, Hoffman EW, Pan L, Ritter G, Villella J, Thomas B, Rodabaugh K, Lele S, Shrikant P, Old LJ, Gnjatic S. Vaccination with an NY-ESO1 peptide of HLA class I/II specificities induces integrated humoral and T cell responses in ovarian cancer. Proc Natl Acad Sci U S A 2007;104: 12837-42.

[99] Chianese-Bullock KA, Irvin WP, Jr., Petroni GR, Murphy C, Smolkin M, Olson WC, Coleman E, Boerner SA, Nail CJ, Neese PY, Yuan A, Hogan KT, Slingluff CL, Jr. A multipeptide vaccine is safe and elicits T-cell responses in participants with advanced stage ovarian cancer. J Immunother 2008;31: 420-30.

[100] Hernando JJ, Park TW, Fischer HP, Zivanovic O, Braun M, Polcher M, Grunn U, Leutner C, Potzsch B, Kuhn W. Vaccination with dendritic cells transfected with mRNA-encoded folate-receptoralpha for relapsed metastatic ovarian cancer. Lancet Oncol 2007;8: 451-4.

[101] Kandalaft LE, Powell DJ, Jr., Chiang CL, Tanyi J, Kim S, Bosch M, Montone K, Mick R, Levine BL, Torigian DA, June $\mathrm{CH}$, Coukos $\mathrm{G}$. Autologous lysate-pulsed dendritic cell vaccination followed by adoptive transfer of vaccine-primed ex vivo co-stimulated $T$ cells in recurrent ovarian cancer. Oncoimmunology 2013;2: e22664.

[102] Brossart P, Wirths S, Stuhler G, Reichardt VL, Kanz L, Brugger W. Induction of cytotoxic Tlymphocyte responses in vivo after vaccinations with peptide-pulsed dendritic cells. Blood 2000;96: 3102-8.

[103] Hernando JJ, Park TW, Kubler K, Offergeld R, Schlebusch H, Bauknecht T. Vaccination with autologous tumour antigen-pulsed dendritic cells in advanced gynaecological malignancies: clinical and immunological evaluation of a phase I trial. Cancer Immunol Immunother 2002;51: 45-52.

[104] Ghiringhelli F, Menard C, Puig PE, Ladoire S, Roux S, Martin F, Solary E, Le Cesne A, Zitvogel L, Chauffert B. Metronomic cyclophosphamide regimen selectively depletes CD4+CD25+ regulatory $T$ cells and restores $\mathrm{T}$ and NK effector functions in end stage cancer patients. Cancer Immunol Immunother 2007;56: 641-8.

[105] Nars MS, Kaneno R. Immunomodulatory effects of low dose chemotherapy and perspectives of its combination with immunotherapy. Int J Cancer 2012;132: 2471-8. 
[106] Barnett B, Kryczek I, Cheng P, Zou W, Curiel TJ. Regulatory T cells in ovarian cancer: biology and therapeutic potential. Am J Reprod Immunol 2005;54: 369-77.

[107] Hodi FS, Mihm MC, Soiffer RJ, Haluska FG, Butler M, Seiden MV, Davis T, Henry-Spires R, MacRae S, Willman A, Padera R, Jaklitsch MT, Shankar S, Chen TC, Korman A, Allison JP, Dranoff G. Biologic activity of cytotoxic $T$ lymphocyte-associated antigen 4 antibody blockade in previously vaccinated metastatic melanoma and ovarian carcinoma patients. Proc Natl Acad Sci U S A 2003;100: 4712-7.

[108] Hodi FS, Butler M, Oble DA, Seiden MV, Haluska FG, Kruse A, Macrae S, Nelson M, Canning C, Lowy I, Korman A, Lautz D, Russell S, Jaklitsch MT, Ramaiya N, Chen TC, Neuberg D, Allison JP, Mihm MC, Dranoff G. Immunologic and clinical effects of antibody blockade of cytotoxic T lymphocyteassociated antigen 4 in previously vaccinated cancer patients. Proc Natl Acad Sci U S A 2008;105: 3005-10.

[109] Topalian SL, Hodi FS, Brahmer JR, Gettinger SN, Smith DC, McDermott DF, Powderly JD, Carvajal RD, Sosman JA, Atkins MB, Leming PD, Spigel DR, Antonia SJ, Horn L, Drake CG, Pardoll DM, Chen L, Sharfman WH, Anders RA, Taube JM, McMiller TL, Xu H, Korman AJ, Jure-Kunkel M, Agrawal S, McDonald D, Kollia GD, Gupta A, Wigginton JM, Sznol M. Safety, Activity, and Immune Correlates of Anti-PD-1 Antibody in Cancer. N Engl J Med 2012.

[110] Brahmer JR, Tykodi SS, Chow LQ, Hwu WJ, Topalian SL, Hwu P, Drake CG, Camacho LH, Kauh J, Odunsi K, Pitot HC, Hamid O, Bhatia S, Martins R, Eaton K, Chen S, Salay TM, Alaparthy S, Grosso JF, Korman AJ, Parker SM, Agrawal S, Goldberg SM, Pardoll DM, Gupta A, Wigginton JM. Safety and activity of anti-PD-L1 antibody in patients with advanced cancer. N Engl J Med 2012;366: 2455-65.

[111] Hamid O, Carvajal RD. Anti-programmed death-1 and anti-programmed death-ligand 1 antibodies in cancer therapy. Expert Opin Biol Ther 2013. 
Figure 1: Réseau immunitaire dans le cancer épithélial de l'ovaire (CEO). Le CEO est immunogénique et exprime des antigènes associés à la tumeur, tels que HER2/neu, Ca125 et le récepteur au folate a $(\mathrm{FR} \alpha)$. Des effecteurs immuns comme les lymphocytes T CD8 ${ }^{+}$ou les natural killer (NK) peuvent reconnaître et détruire les cellules tumorales ovariennes. Mais le microenvironnement immunosuppresseur supprime cette action antitumorale. Les lymphocytes $\mathrm{T}$ régulateurs, les cellules dendritiques tolérogènes, les macrophages associés au tumeur $\left(\mathrm{B} 7-\mathrm{H}^{+}\right)$ou encore des cellules non immunitaires comme les cellules souches mésenchymateuses (MSC) ou la cellule tumorale elle-même altèrent l'activité anti-tumorale des cellules effectrices immunitaires à travers des mécanismes de contacts inter-cellulaires ou par l'intermédiaire de facteurs solubles comme l'interleukine 10 (IL-10), le transforming Growth factor (TGF- $\beta$ ), l'indoleamine 2,3-dioxygénase (IDO) ou la prostaglandine E2. Les contacts intercellulaire immunosuppresseurs peuvent utiliser le couple ligand récepteur Programmed Death $1 /$ Programmed Death Ligand 1 (PD-L1). Cytotoxic T-lymphocyteassociated antigen 4 (CTLA-4) est un autre exemple d'un « checkpoint » immunosuppresseur du microenvinnement tumoral ovarien.

Immune network in Epithelial Ovarian Carcinoma (EOC). EOC is immunogenic and express tumor associated antigen such as HER2/neu, Ca125 or Folate Receptor a (FRa). Various immune effectors such as CD8+ T cell or Natural Killer (NK) can attack tumor cells, but immunosuppressive crosstalks counteract effector cell attacks. Regulatory T cells, tolerogenic dendritic cells (DC), B7-H4+ macrophages or non immune cells such as mesenchymal stem cells (MSC) or tumor cells themself halt immune antitumor activities through cell-cell contacts or soluble factors (i.e. IL-10, TGF-b, indoleamine 2,3-dioxygenase (IDO), prostaglandine E2 (PGE2)). For example, immunosuppressive cell-cell contacts involve Programmed Death 1 / Programmed Death Ligand 1 (PD-L1) pathway. Cytotoxic Tlymphocyte-associated antigen 4 (CTLA-4) is an other example of immunosuppressive chekpoint in tumor microenvironment. 


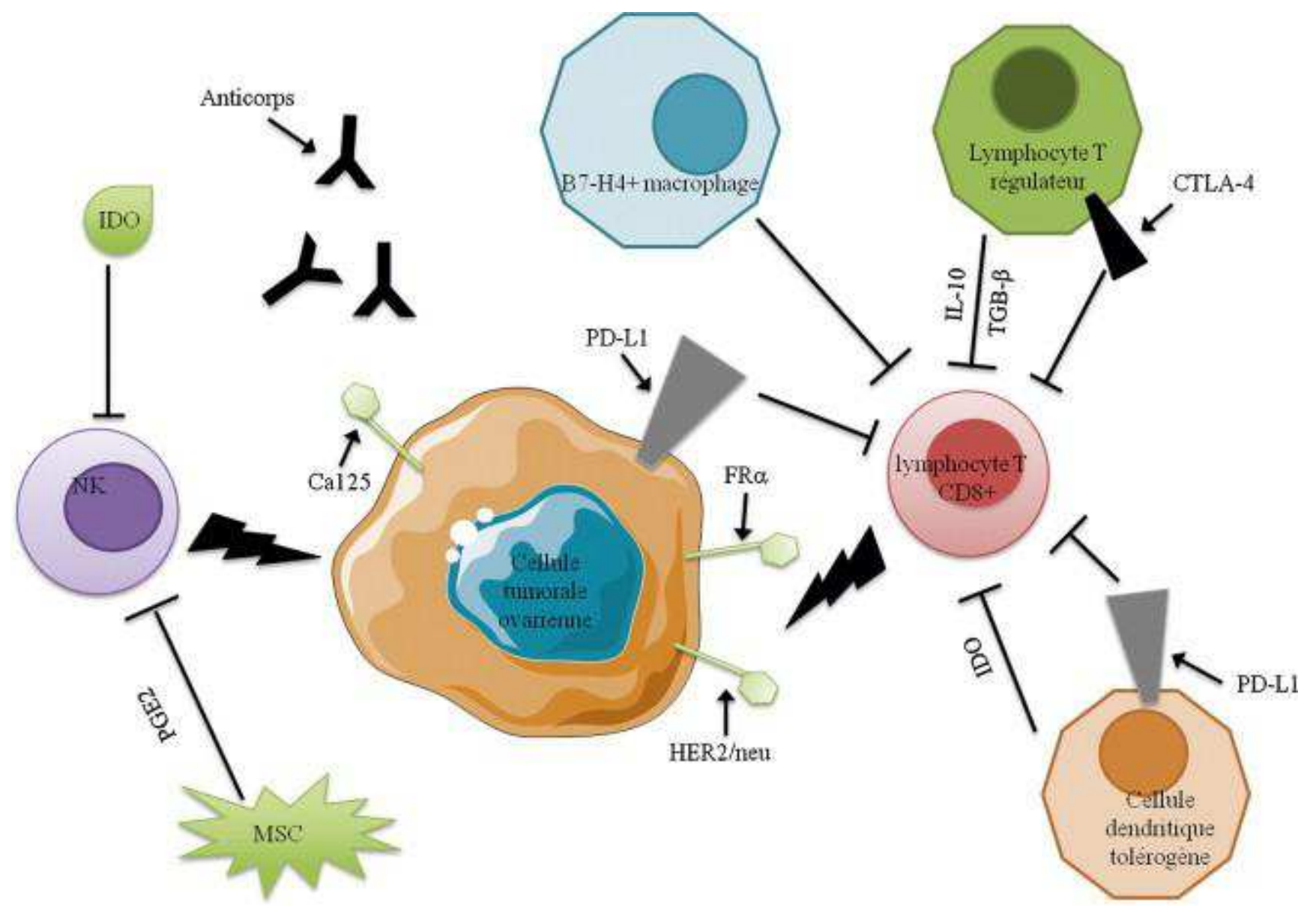


Tableau 1: Implication des lymphocytes intra-tumoraux (TIL) dans l'amélioration du pronostic du cancer epithelial de l'ovaire

Table 1 : Intratumoral lymphocytes and prognosis in epithelial ovarian carcinoma

\begin{tabular}{|c|c|c|}
\hline Auteurs & Année & Découvertes \\
\hline Zhang L [17] & 2003 & $\begin{array}{l}\text { Association entre l'infiltration intra-tumorale }\left(\mathrm{TIL} \mathrm{CD}^{+}\right) \text {et la } \\
\text { survie des patientes }\end{array}$ \\
\hline Raspollini NR [20] & 2005 & $\begin{array}{l}\text { Association entre l'infiltration intra-tumorale (TIL } \mathrm{CD}^{+} \text {) et la } \\
\text { survie des patientes (et de la réponse à la chimiothérapie) }\end{array}$ \\
\hline Sato E [21] & 2005 & $\begin{array}{l}\text { Association entre l'infiltration intra-tumorale }\left(\mathrm{TIL} \mathrm{CD} 8^{+}\right) \text {et la } \\
\text { survie des patientes }\end{array}$ \\
\hline Hamanishi J [22] & 2007 & $\begin{array}{l}\text { Association entre l'infiltration intra-tumorale }\left(\mathrm{TIL} \mathrm{CD}^{+}\right) \text {et la } \\
\text { survie des patientes }\end{array}$ \\
\hline Clarke B [23] & 2008 & $\begin{array}{l}\text { Association entre l'infiltration intra-tumorale }\left(\mathrm{TIL} \mathrm{CD} 8^{+}\right) \text {et la } \\
\text { survie des patientes (seulement pour les cancers épithéliaux de } \\
\text { l'ovaire de séreux de haut grade, pas pour les sous types } \\
\text { endométriö̈des ou mucineux) }\end{array}$ \\
\hline Shah CA [24] & 2008 & $\begin{array}{l}\text { Association entre l'infiltration intra-tumorale }\left(\mathrm{TIL} \mathrm{CD}^{+}\right) \text {et } \\
\text { une chirurgie de debulking optimale. }\end{array}$ \\
\hline Tomsova M [25] & 2008 & $\begin{array}{l}\text { Association entre l'infiltration intra-tumorale }\left(\mathrm{TIL} \mathrm{CD}^{+}\right) \text {et la } \\
\text { survie des patientes }\end{array}$ \\
\hline Callahan MJ [26] & 2008 & $\begin{array}{l}\text { Association entre l'infiltration intra-tumorale }\left(\mathrm{TIL} \mathrm{CD}^{+}\right) \text {et la } \\
\text { survie des patientes }\end{array}$ \\
\hline Han LY [27] & 2008 & $\begin{array}{l}\text { Association entre l'infiltration intra-tumorale }\left(\mathrm{TIL} \mathrm{CD}^{+} \text {et }\right. \\
\mathrm{CD}^{+} \text {) et la survie des patientes }\end{array}$ \\
\hline Stumpf M [28] & 2009 & $\begin{array}{l}\text { Association entre l'infiltration intra-tumorale }\left(\mathrm{TIL} \mathrm{CD}^{+} \text {et }\right. \\
\mathrm{CD}^{+} \text {) et la survie des patientes }\end{array}$ \\
\hline Leffers N $[29,30]$ & 2009 & $\begin{array}{l}\text { Association entre l'infiltration intra-tumorale }\left(\mathrm{TIL} \mathrm{CD} 8^{+}\right) \text {et la } \\
\text { survie des patientes }\end{array}$ \\
\hline Milne K [31] & 2009 & $\begin{array}{l}\text { Association entre l'infiltration intra-tumorale }\left(\mathrm{TIL} \mathrm{CD}^{+} \text {et }\right. \\
\mathrm{CD}^{+} \text {) et la survie des patientes }\end{array}$ \\
\hline Adams SF [32] & 2009 & $\begin{array}{l}\text { Association entre l'infiltration intra-tumorale }\left(\mathrm{TIL} \mathrm{CD}^{+} \text {et }\right. \\
\mathrm{CD}^{+} \text {) et la survie des patientes }\end{array}$ \\
\hline Kryczek I [33] & 2009 & Association entre l'infiltration intra-tumorale (TIL $\mathrm{CD}^{+}{ }^{+}$avec \\
\hline
\end{tabular}


Tableau 2: Infiltration tumorale par des cellules immunitaires tolérogènes et pronostic du cancer épithélial de l'ovaire (CEO).

Table 2: Immune escape and prognosis in epithelial ovarian carcinoma.

\begin{tabular}{|c|c|c|}
\hline Auteurs & Année & Découvertes \\
\hline Curiel TJ [45] & 2004 & $\begin{array}{l}\text { L'infiltration intratumorale de lymphocytes } \mathrm{T} \text { régulateurs } \\
\left(\mathrm{CD} 4^{+} \mathrm{CD} 25^{+} \mathrm{FoxP}^{+}\right) \text {est corrélée à un mauvais pronostic }\end{array}$ \\
\hline Wolf D [46] & 2005 & 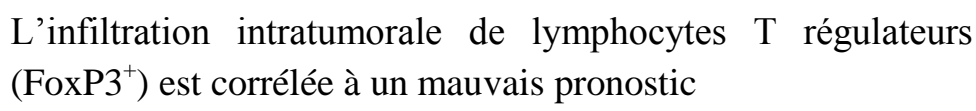 \\
\hline Dong HP [47] & 2006 & $\begin{array}{l}\text { L'infiltration intratumorale de } \mathrm{NK}\left(\mathrm{CD}^{-} \mathrm{CD} 16^{+}\right) \text {ou de } \\
\text { lymphocytes } \mathrm{B}\left(\mathrm{CD} 19^{+}\right) \text {est corrélée à un mauvais pronostic }\end{array}$ \\
\hline Kryczek I [48] & 2007 & $\begin{array}{l}\mathrm{L}^{\prime} \text { infiltration intratumorale de macrophage } \mathrm{B} 7-\mathrm{H}^{+} \text {ou } \\
\text { lymphocytes } \mathrm{T} \text { régulateurs }\left(\mathrm{CD} 4^{+} \mathrm{CD} 25^{+} \mathrm{FoxP} 3^{+}\right) \text {est corrélée à } \\
\text { un mauvais pronostic }\end{array}$ \\
\hline Hamanishi J [22] & 2007 & $\begin{array}{l}\text { L'expression par la tumeur de PD-L1 est corrélée à une } \\
\text { diminution de l'infiltration intra-tumorale par les lymphocytes } \\
\mathrm{T}\end{array}$ \\
\hline Buckanovitch RJ [49] & 2008 & $\begin{array}{l}\text { L'expression par les cellules endothéliales vasculaires du } \\
\text { récepteur à l'endothelin } \mathrm{B}\left(\mathrm{ET}_{\mathrm{B}} \mathrm{R}\right) \text { réduit l'infiltration de la } \\
\text { tumeur par les lymphocytes } \mathrm{T} \text { et est corrélée à une diminution } \\
\text { de la survie }\end{array}$ \\
\hline Labidi-Galy SI [50] & 2011 & $\begin{array}{l}\text { L'infiltration intra-tumorale par les cellules dendritiques } \\
\text { plasmacytoïdes de phénotype } \mathrm{CD} 4^{+} \mathrm{CD}^{+} 23^{+} \mathrm{BDCA}^{+} \text {est } \\
\text { corrélée à un mauvais pronostic }\end{array}$ \\
\hline Conrad C [51] & 2012 & 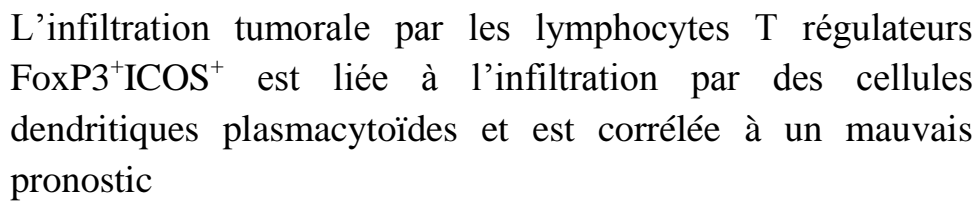 \\
\hline
\end{tabular}

PD-1: programmed cell death 1; PD-L1: PD-1 ligand 1; $\mathrm{ET}_{\mathrm{B}} \mathrm{R}$ : endothelin $\mathrm{B}$ receptor; 
Tableau 3 : Essais cliniques d'immunothérapies passives dans le cancer épithélial de l'ovaire

Table 3: Clinical trials using passive immunotherapy in epithelial ovarian carcinoma

Etudes cliniques d'immunothérapie utilisant des Anticorps

\begin{tabular}{|c|c|c|c|c|c|}
\hline Auteurs et année & $\begin{array}{l}\text { Anticorps } \\
\text { utilisé }\end{array}$ & $\begin{array}{l}\text { Antigène } \\
\text { ciblé }\end{array}$ & $\begin{array}{l}\text { Phase } \\
\text { clinique }\end{array}$ & $\begin{array}{l}\text { Nombre de } \\
\text { patientes } \\
\text { inclues }\end{array}$ & $\begin{array}{l}\text { Efficacité } \\
\text { thérapeutique }\end{array}$ \\
\hline $\begin{array}{l}\text { Berek JS, } 2009 \text { [79] } \\
\text { Ehlen TG, } 2005 \text { [80] }\end{array}$ & $\begin{array}{l}\text { Oregovoma } \\
\text { b }\end{array}$ & Ca125 & I/II/III & 403 & $\begin{array}{ll}\text { Variables, fonction } \\
\text { des études }\end{array}$ \\
\hline Reinartz S, 2004 [81] & $\begin{array}{l}\text { Abagovom } \\
\text { ab }\end{array}$ & $\mathrm{Ca} 125$ & $\mathrm{I} / \mathrm{II}$ & 119 & $\begin{array}{l}\text { Amélioration de la } \\
\text { survie de } 2 \text { mois }\end{array}$ \\
\hline $\begin{array}{l}\text { Bookman MA, } 2003 \\
\text { [82] }\end{array}$ & $\begin{array}{l}\text { Trastuzuma } \\
\text { b }\end{array}$ & Her2/neu & II & 41 & $1 \mathrm{RC}, 2 \mathrm{RP}$ \\
\hline $\begin{array}{l}\text { Gordon MS, } 2006 \text { [83] } \\
\text { Makhija S, } 2010 \text { [84] }\end{array}$ & Pertuzumab & HER2/neu & II & 387 & $\begin{array}{l}\text { Pas d'amélioration } \\
\text { de la survie }\end{array}$ \\
\hline Langdon SP, 2010 [85] & & & & & \\
\hline Konner JA, 2010 [86] & $\begin{array}{l}\text { Farletuzum } \\
\text { ab }\end{array}$ & $\mathrm{FR} \alpha$ & $\mathrm{I} / \mathrm{II}$ & 69 & $\begin{array}{l}35 \% \text { des patientes } \\
\text { avec maladie stable }\end{array}$ \\
\hline $\begin{array}{l}\text { Spannuth WA, } 2010 \\
\text { [87] }\end{array}$ & & & & & \\
\hline Burges A, 2007 [88] & $\begin{array}{l}\text { catumaxom } \\
\text { ab }\end{array}$ & EpCAM & $\begin{array}{l}\text { Phase } \\
\text { II/III }\end{array}$ & 129 & 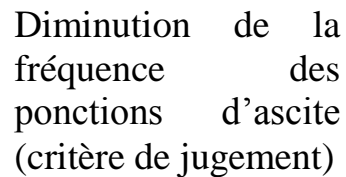 \\
\hline
\end{tabular}

Etudes cliniques d'immunothérapie adoptive (utilisant des cellules cytotoxiques)

\begin{tabular}{|c|c|c|c|c|c|}
\hline Auteurs et année & $\begin{array}{l}\text { Cellules } \\
\text { utilisées }\end{array}$ & $\begin{array}{l}\text { Site } \\
\text { d'inject } \\
\text { ion }\end{array}$ & $\begin{array}{l}\text { Phase } \\
\text { clinique }\end{array}$ & $\begin{array}{l}\text { Nombre de } \\
\text { patientes } \\
\text { inclues }\end{array}$ & $\begin{array}{l}\text { Efficacité } \\
\text { thérapeutique }\end{array}$ \\
\hline Aoki Y, 1991 [90] & $\mathrm{TIL} \mathrm{CD}^{+}$ & IV & I & 17 & $\begin{array}{l}14 \mathrm{RO}: 8 \mathrm{RC} \text { et } 6 \\
\mathrm{RP}\end{array}$ \\
\hline $\begin{array}{l}\text { Freedman } \\
\text { [91] }\end{array}$ & $\begin{array}{l}\mathrm{TIL} \mathrm{CD}^{+} \text {et } \\
\mathrm{CD} 8^{+}\end{array}$ & IP & I & 8 & $4 \mathrm{RO}: 3 \mathrm{RP}$ et $1 \mathrm{MS}$ \\
\hline Fujita K, 1995 [92] & $\mathrm{TIL} \mathrm{CD}^{+}$ & IV & I & 13 & $\begin{array}{l}\text { Augmentation des } \\
\text { survies sans récidive } \\
\text { et globale }\end{array}$ \\
\hline
\end{tabular}




$\begin{array}{llllll}\begin{array}{l}\text { Kershaw MH, 2006 } \\ \text { [93] }\end{array} & \begin{array}{l}\text { Lymphocytes IV } \\ \text { T autologue } \\ \text { éduqués contre } \\ \text { FRa }\end{array} & \text { I } & & & \begin{array}{l}\text { Pas de réponse } \\ \text { clinique }\end{array} \\ \begin{array}{l}\text { Dobrzanski } \\ {[94]}\end{array} \text { MJ, 2009 } \begin{array}{l}\text { Lymphocytes IP } \\ \text { T autologues } \\ \text { éduqués contre } \\ \text { Ca15.3 }\end{array} & \text { I } & 7 & \begin{array}{l}\text { 2 RO (diminution du } \\ \text { Ca125 et survie } \\ \text { prolongée) : }\end{array}\end{array}$

RC : Réponse complète ; RP : Réponse partielle ; RO : Réponse objective ; MS : Maladie Stable ; TIL : lymphocytes intratumoraux ; IV : intra-veineux ; IP : intra-péritonéal ; FR $\alpha$ : Récepteur $\alpha$ aux folates

Tableau 4 : Essais cliniques basés sur une vaccination peptidique ou cellulaire dans le cancer épithélial de l'ovaire

Table 4: Clinical trials using active immunotherapy in epithelial ovarian carcinoma

\begin{tabular}{|c|c|c|c|c|}
\hline \multicolumn{5}{|c|}{ Vaccination peptidique } \\
\hline Auteur et année & Peptide testé & $\begin{array}{l}\text { Phase } \\
\text { clinique }\end{array}$ & $\begin{array}{l}\text { Nombre de } \\
\text { patientes }\end{array}$ & Efficacité thérapeutique \\
\hline $\begin{array}{l}\text { Chianese-Bullock } \\
\text { KA, } 2008 \text { [99] }\end{array}$ & $\begin{array}{l}\text { Fusion de } \\
\text { HER2/neu- } \\
\text { FR } \alpha-M A G E\end{array}$ & I & 9 & $\begin{array}{l}\text { Réponse immunitaire, Pas de } \\
\text { réponse clinique }\end{array}$ \\
\hline $\begin{array}{l}\text { Diefenbach } \quad \text { CS, } \\
2008 \text { [97] }\end{array}$ & NY-ESO-1 & I & 9 & $\begin{array}{l}\text { Réponse immunitaire, } \\
\text { réponse clinique non évaluée }\end{array}$ \\
\hline Leffers N, 2009 [96] & P53 & II & 20 & $\begin{array}{l}\text { Réponse immunitaire, une } \\
\text { patiente avec maladie stable }\end{array}$ \\
\hline Disis ML, 2002 [95] & HER2/neu & I & 64 & $\begin{array}{l}\text { Réponse immunitaire, } \\
\text { réponse clinique non évaluée }\end{array}$ \\
\hline \multicolumn{5}{|l|}{ Vaccination cellulaire } \\
\hline Auteur et année & $\begin{array}{l}\text { Peptide } \\
\text { présenté par } \\
\text { la cellule } \\
\text { dendritique }\end{array}$ & $\begin{array}{l}\text { Phase } \\
\text { clinique }\end{array}$ & $\begin{array}{l}\text { Nombre de } \\
\text { patientes }\end{array}$ & Efficacité thérapeutique \\
\hline $\begin{array}{lll}\text { Brossart } & P, & 2000 \\
{[102]} & & \end{array}$ & HER2/neu & $\mathrm{I}$ & 10 & $\begin{array}{l}\text { Réponse immunitaire, } \\
\text { réponse clinique non évaluée }\end{array}$ \\
\hline $\begin{array}{l}\text { Hernando JJ, } 2002 \\
{[103]}\end{array}$ & $\begin{array}{l}\mathrm{Ag} \text { de tumeur } \\
\text { autologue }\end{array}$ & $\mathrm{I}$ & 8 & $\begin{array}{l}\text { Réponse immunitaires, } 2 \\
\text { patientes avec une maladie } \\
\text { stable }\end{array}$ \\
\hline
\end{tabular}


